\title{
ASPECTOS BIOLÓGICOS E MORFOLÓGICOS DE MIGDOLUS FRYANUS (WESTWOOD, 1863) (COLEOPTERA: VESPERIDAE)
}

\section{L.A. Machado ${ }^{1}$, M. Habib ${ }^{2}$, L.G. Leite ${ }^{1}$, L.C. Carregari ${ }^{1}$}

${ }^{1}$ Instituto Biológico, Centro Experimental Central, CP 70, CEP 13001-970, Campinas, SP, Brasil. E-mail laertemachado@biologico.sp.gov.br

\author{
RESUMO
}

Neste estudo machos e fêmeas de Migdolus fryanus foram coletados em campo, após o acasalamento e trazidos ao laboratório. Fêmeas foram individualizadas em baldes de plástico (20 L) contendo solo. Observou-se o número de ovos, o tamanho, a viabilidade, o período de incubação e o tamanho das larvas ao eclodirem. Dimensões de larvas recém-eclodidas e ovos foram obtidas com um micrômetro ocular de escala de $0,05 \mathrm{~mm}$. Machos foram mantidos em cilindros de vidros $(12 \mathrm{~cm}$ alt. X $12 \mathrm{~cm} \varnothing)$, fechados com placas de Petri $(15 \mathrm{~cm}$ de $\varnothing)$ e definida a longevidade. Utilizando-se 50 larvas estudou-se uma dieta artificial, na qual foi acrescida 50 g de cana-de-açúcar "in natura" moída. Para os estudos morfológicos, os adultos foram coletados em cana-de-açúcar, pastagens e café abandonado, e os caracteres foram observados com microscópio óptico. As medições para adultos e larvas maduras foram tomadas com paquímetro, de escala de $1 \mathrm{~mm}$. Fêmeas depositaram 19 a 38 ovos / fêmea (X $29,4 \pm 5,5)$, com viabilidade de 65 a $98 \%(\bar{X} 84,9 \pm 11,6)$ e período de incubação de 17 a 25 dias $(\bar{X} 20,6 \pm 0,9)$. Os ovos têm formato oval e mediram 3 a 5 $\mathrm{mm}(\bar{X} 4,5 \pm 3,7)$. A longevidade das fêmeas variou de 28 a 38 dias $(\bar{X} 32,5 \pm 3,5)$ e de machos de 3 a 9 dias $(\bar{X} 5,8 \pm 1,9)$. Larvas ao eclodirem mediram entre $4 \mathrm{a} 6 \mathrm{~mm}$. Na dieta as larvas foram mantidas por 2 anos, passando por 6 e 7 ecdises, mas não completaram o ciclo ovo-adulto. Os adultos apresentaram grandes variações morfológicas, tanto em dimensões quanto em coloração. Apenas a espécie $M$. fryanus foi constatada nos municípios estudados.

PALAVRAS-CHAVE: Migdolus fryanus, cana-de-açúcar, biologia, morfologia, dieta artificial.

\section{ABSTRACT}

BIOLOGICAL AND MOPRHPLOGICAL ASPECTS OF MIGDOLUS FR YANUS (WESTWOOD, 1863) (COLEOPTERA: VESPERIDAE). Males and females of the species Migdolus fryanus were collected in sugarcane fields after mating and taken to the laboratory for morphological and biological investigations. Females were individualized in plastic containers in the soil $(20 \mathrm{~L})$. The newly hatched larvae and the eggs dimensions were measured with an ocular micrometer with $0.05 \mathrm{~mm}$ precision. Males were maintained in glass cylinders $(12 \mathrm{~cm}$ height by $12 \mathrm{~cm} \varnothing)$, closed with Petri dishes $(15 \mathrm{~cm} \varnothing)$, in order to get the longevity data. An artificial and modified diet was studied, supplemented with $50 \mathrm{~g}$ of triturated sugarcane. For the morphological observations, the insects were collected from sugarcane fields, pastures and abandoned coffee crop, and the material was examined by means of on optical microscope. The adults and larvae were measured using a calipers with 1-mm precision. The females laid from 19 to 38 eggs, with an average of $29.4 \pm 5.5$. The egg viability ranged from 65 to $98 \%$ with the average of $84.9 \pm 11.6 \%$ and incubation period of 17 to 25 days, with de average of $20.6 \pm 0.9$ days. The egg length ranged from 3 to $5 \mathrm{~mm}$. Female longevity ranged from 28 to 38 days, with an average of $32.5 \pm 3.5$ days, and the males from 3 to 9 days, with an average of $5.8 \pm 1.9$ days. The newly hatched larvae measured from 4 to $6 \mathrm{~mm}$ in length. The larvae were maintained on the artificial and modified diet for 2 years, passing through 6 and 7 moults. The adults showed significant color and size variations, but only the species $M$. fryanus was detected.

KEY WORDS: Migdolus fryanus sugarcane, biology, morphology, artificial diet.

\footnotetext{
${ }^{2}$ Universidade Estadual de Campinas, Campinas, SP, Brasil.
} 


\section{INTRODUÇÃO}

A subfamília Anoplodermatinae GUÉRINMénEvilLE (1840), a qual pertence o gênero Migdolus, foi considerada como subfamília de Cerambycidae por Duffy (1953) eCrowson (1955). No entanto,SvÁcHA et al. (1997) a transferiram para a família Vesperidae.

A espécie Migdolus fryanus (Westwood 1863), o besouro da raiz ou broca do rizoma da cana-deaçúcar, é uma das principais pragas da cultura, ocorrendo, principalmente, nas localidades de solo arenoso, no centro-sul da América doSul (TeRÁn et al.,1983; KASTENJUNIORet al.1985). Segundo Nunes Junior (1996) a espécie foi constatada nos Estados de Goiás, Mato Grosso, Mato Grosso doSul, Paraná, São Paulo, Santa Catarina, na Argentina (Província de Corrientes) eno Paraguai.

Embora constatada na cultura da cana-de-açúcar, em 1927 (LANE, 1937), M. fryanus é pouco conhecida e não se sabe seéa única espécie do gênero relacionada com a cultura (NAKANO \& JoKо, 1969; RocCia, 1977; TERÁn et al., 1983; TERÁn et al., 1984; Bentoet al., 1992)

GounelLe (1899) e BRUCH (1921) foram os primeiros a registrar dados sobre as atividades biológicas dos adultos de duas espécies de Anoplodermatini. O primeiro fez referência aM. fryanus, no Vale do Rio Pardo, SP, em 1898, informando que a fêmea tem hábito subterrâneo e que ambos os sexos foram encontrados ao longo de pequenos caminhos, depois das chuvas. Ain$\mathrm{da}$, esse autor relata que o macho era bastante ativo, voava bem, ao passoque a fêmea era vagarosa e de asas posteriores bastante reduzidas. Já o segundo autor, citou observações realizadas em 1918, por DiuRIone, curador do Museu de La Plata, o qual informava que a fêmea de M.orbignyi Blanchard, foi encontrada no solo a pouca profundidade e que três machos procuravam penetrar na terra. Após alguns dias, pelo período da manhã, o observador teve a oportunidade de coletar mais um casal da espécie. Na ocasião, a fêmea se encontrava com a metade do corpo para fora da terra e o macho ao redor dela, muito agitado.

Os adultos de $M$. fryanus têm vida efêmera; vivem pouco tempo após a cópula e a postura. Em contraposição, a fase larval é longa, quase sempre de um ano, podendo prolongar-se em dois ou três (BENTO et al., 1995; NAKANOet al., 2001). As larvas de M. fryanus têm hábito subterrâneo, podendo atingir até 4 a 5 metros de profundidade (ARRIGONI, 1988). O que se conhece sobre esse coleóptero refere-se apenas aos primeiros $60 \mathrm{~cm}$ de profundidade no solo (TERÁN etal., 1984; ArRigoni et al., 1986). Concomitantemente, em função da dificuldade de realizar estudos nas camadas mais profundas, presume-se que as informações até agora obtidas sobre o inseto sejam apenas de uma parte da população, aspecto que pode estar dificultando o emprego de métodos de controle eficientes.
Com relação à taxonomia do grupo que foi revista por Dias (1984) relatando 10 espécies no gênero, atualmente pouco se conhece sobre quais espécies estão relacionadas à cultura da cana-de-açúcar. $\mathrm{O}$ objetivo desse estudo foi ampliar os conhecimentos sobre biologia, e morfologia de $M$. fryanus, assim como conhecer quais espécies do gênero estão associadas à cultura da cana-de-açúcar no Estado de São Paulo.

\section{MATERIAL E MÉTODOS}

Para o estudo da biologia um grupo de 28 machos e 16 fêmeas foi coletado em canaviais, logo após o acasalamento, nos Municípios de Olímpia, SP (latitude $20^{\circ} 44^{\prime} 14^{\prime \prime}$ Sul, longitude $48^{\circ} 54^{\prime} 53^{\prime \prime}$ Oeste ealtitude $506 \mathrm{~m}$ ), Catanduva, SP (latitude $21^{\circ} 08^{\prime} 16^{\prime \prime}$ sul, longitude $48^{\circ} 58^{\prime} 22^{\prime \prime}$ Oeste ealtitude $503 \mathrm{~m}$ ), Promissão, SP (latitude $21^{\circ} 32^{\prime} 12^{\prime \prime}$ Sul, longitude $49^{\circ} 51^{\prime} 21^{\prime \prime}$ Oeste e altitude $426 \mathrm{~m}$ ) e Teodoro Sampaio, SP (latitude $22^{\circ}$ $31^{\prime} 57^{\prime \prime}$ Sul, longitude $52^{\circ} 10^{\prime} 03^{\prime \prime}$ Oeste e altitude 321 $\mathrm{m})$. Os insetos foram individualizados em frascos de vidro ( $15 \mathrm{~cm}$ de altura por $8 \mathrm{~cm}$ de $\varnothing$ ), contendo solo, sendo imediatamente acondicionados em caixas de isopor, e transportados ao laboratório para a realização das pesquisas.

No laboratório as fêmeas foram individualizadas em baldes de plástico (20 L), contendo solo arenoso para obtenção das posturas. Observou-se diariamente o número de ovos colocados por fêmeas, o tamanho dos ovos, a viabilidade o período de incubação e o tamanho das larvas recém eclodidas. Para a eclosão das larvas os ovos foram mantidos individualizados em potes de plásticos ( $3 \mathrm{~cm}$ de altura $X 9 \mathrm{~cm}$ de $\varnothing)$, em sala com $26 \pm 2^{\circ} \mathrm{C}, 70 \pm 10 \%$ U.R. e fotofase de $12 \mathrm{~h}$.

As dimensões dos ovos e das larvas recém eclodidas foram obtidas com auxílio de um micrômetro ocular com escala de $0,05 \mathrm{~mm}$. Já os machos foram conduzidos em cilindros de vidro ( $12 \mathrm{~cm}$ altura $\mathrm{X} 12$ $\mathrm{cm}$ de Ø), fechados nas extremidades por placas de Petri ( $15 \mathrm{~cm}$ de $\varnothing)$ e observado apenas a longevidade. Para parte das larvas recém-eclodidas (50 larvas) estudou-se uma dieta artificial desenvolvida por Machado; Berti Filho (1999), para criação de Diploschema rotundicolle (Serville, 1834) (Coleoptera: Cerambycidae) uma coleobroca associada à cultura dos citros. Nessa dieta foi acrescida em sua receita, 50 g de cana-de-açúcar "in natura" triturada. Como recipiente para a criação foram utilizados tubos de vidro de $8 \mathrm{~cm}$ de comprimento por $2,5 \mathrm{~cm}$ de $\varnothing$, que foram mantidos em sala com $26 \pm 2^{\circ} \mathrm{C}, 70 \pm 10 \%$ U.R. e fotofase de $12 \mathrm{~h}$.

Para as observações morfológicas os insetos foram coletados nos Municípios de Olímpia, Catanduva, Promissão, Teodoro Sampaio, Bady 
Bassitt, SP (latitude $20^{\circ} 55^{\prime} 05^{\prime \prime}$ Sul, longitude $49^{\circ} 26^{\prime}$ $46^{\prime \prime}$ Oeste, e altitude $510 \mathrm{~m}$ ), Potirendaba, SP (latitude $21^{\circ} 02^{\prime} 54^{\prime}$ Sul e longitude $49^{\circ} 22^{\prime} 38^{\prime}$ Oeste e altitude $469 \mathrm{~m}$ ) e Palestina, SP (latitude 20²3'24" Sul, longitude $49^{\circ} 25^{\prime} 59^{\prime \prime}$ Oeste e altitude de $550 \mathrm{~m}$ ), em cultura decana-de-açúcar, pastagens e cafezal abandonado, por intermédio de armadilhas de feromônio sexual. Os insetos foram fixados, por meio de alfinete entomológico, sendo os caracteres examinados em microscópio estereoscópico, e as medições tomadas com auxílio de um paquímetro, com escala de $1 \mathrm{~mm}$. Após os estudos os exemplares foram depositados na Coleção de insetos "Oscar Monte", do Laboratório de Controle Biológico, Instituto Biológico de São Paulo.

\section{RESULTADOS E DISCUSSÃO}

\section{Aspectos biológicos}

A longevidade dos machos foi menor, vivendo um período de 3 a 9 dias $(\bar{X} 5,8 \pm 1,9)$, já as fêmeas viveram de 28 a 38 dias ( $\bar{X} 32,5 \pm 3,5)$ (Tabela 1$)$. Com relação aos dados biológicos referente a ovos e larvas de $M$. fryanus, (Tabela 2), o número de ovos depositados por fêmea variou de 19 a $38(\bar{X} 29,4 \pm 5,5)$ e tiveram uma viabilidade entre 65 a $98 \%(\bar{X} 84,9 \pm 11,6 \%)$. O período de incubação variou de 17 a 25 dias (X 20,6 $\pm 1,0)$.

Roccia (1977) reportou que os machos deM.fryanus vivem em média 2 a 3 dias e as fêmeas por volta de 30 dias ou mais. Em um estudo de laboratório com 25 fêmeas, ARRIGONI (1987) observou longevidade de 20,8 $\pm 2,43$ dias, capacidade média de oviposição de 40,4 \pm 9,5 ovos por fêmea, incubação média de 18,42 $\pm 0,28$ dias, e uma viabilidade de 60\%. ARrigoni (1988), em observações realizadas em câmara climatizada com $25 \pm 1^{\circ} \mathrm{C}$, concluiu que a longevidade média das fêmeas é de 25,9 dias, a média de ovos foi de 34,06 ovos/fêmeas com uma viabilidade de $83,12 \%$. BENTO et al. (1995) relataram que os machos podem viver, em média, 4 a 7 dias e as fêmeas de 7 a 38 dias e que as mesmas depositam de 14 a 45 ovos que tem um período de incubação, em média, de 17 a 23 dias.

Um dos aspectos que dificulta o estudo completo da biologia de $M$. fryanus é a impossibilidade de criá-lo em condições de laboratório. No estudo com dieta artificial foi possível manter larvas por um período de 2 anos (março de 2001 a março de 2003). Esses resultados demonstram que a dieta estudada pode ser utilizada para a criação de larvas de $M$. fryanus, em condições artificiais, para estudos de laboratório.

Embora as larvas se desenvolveram, passando por 6 e 7 ecdises e atingiram 4 a $5 \mathrm{~cm}$ de comprimento, elas não alcançaram os estágios de pupa e adulto. Essas observações deixam a expectativa que em condições naturais deve ocorrer algum estímulo para que o inseto complete o seu desenvolvimento e atinja as demais fases do seu ciclo de vida. Por outro lado, pode-se também inferir que o inseto possui um ciclo biológico longo, podendo passar de um ciclo para outro da cultura como relataram BENTO et al. (1995) e NAKANO et al. (2001). De qualquer modo, não há relato da criação desta espécie e estudos de biologia, sob condições de laboratório.

\section{Aspectos morfológicos}

\section{Adultos}

O tamanho dos besouros foi heterogêneo, os machos variaram de 1,5 a $2,6 \mathrm{~cm}$ de comprimento $(X 2,1$ $\pm 0,3)$ e as fêmeas de 1,7 a 2,2 cm (X 1,9 $\pm 0,15)$.

Dias (1984) ao revisar a subfamília Anoplodermatinae atribuiu a espécie $M$. fryanus dimensões do corpo variável de 1,21 a $3,7 \mathrm{~cm}$ para os machos e de 1,95 a 3,5 cm para as fêmeas. TERÁN et al. (1984) relataram que adultos de $M$. fryanus medem entre 1,8 a $2,5 \mathrm{~cm}$ e que o tamanho do ovo varia de 6 a $7 \mathrm{~mm}$.

O gênero Migdolus apresenta 10 espécies, conforme revisão de DiAs (1984). No presente estudo, foi constatada apenas a espécie M. fryanus nos exemplares coletados. Os machos observados apresentaram antenas maiores que as fêmeas (Fig. $1 \mathrm{~A}$ ) atingindo um pouco mais que a metade do corpo, com 11 antenômeros, sendo o escapo curto, oblongo e com pontuação discreta. $\mathrm{O}$ articulo 3 é denteado e mais longo que o articulo 4. As fêmeas possuem antenas menores (Fig. 1B) com 8 artículos, sendo o $3^{\circ}$ alongado e mais afilado na base, pouco ou não denteado. $O$ escapo é mais longo e menos oblongo.

Tabela 1 - Tamanho e longevidade de adultos de Migdolus fryanus coletados nos Municípios de Olímpia, Catanduva, Promissão, Teodoro Sampaio, Bady Bassitt, Potirendaba e Palestina, SP) (26 $\pm 2^{\circ}$ C, $70 \pm 10 \%$ U.R. e fotofase de 12h).

\begin{tabular}{llccc}
\hline Observações & Fêmeas & $\bar{X} \pm$ EP & Machos & $\bar{X} \pm$ EP \\
\hline Tamanho (cm) & $1,7-2,2$ & $(1,9 \pm 0,15)$ & $1,5-2,6$ & $(2,1 \pm 0,30)$ \\
Longevidade (dias) & $28-38$ & $(32,5 \pm 3,5)$ & $3-9$ & $(5,8 \pm 1,9)$ \\
\hline
\end{tabular}

EP = Erro padrão 
Tabela 2 - Parâmetros biológicos das fases imaturas de Migdolus fryanus coletados em 4 Municípios do estado de São Paulo (Olímpia, Catanduva, Promissão, Teodoro Sampaio) $\left(26 \pm 2^{\circ} \mathrm{C}, 70 \pm 10 \%\right.$ U.R. e fotofase de $\left.12 \mathrm{~h}\right)$.

\begin{tabular}{lcl}
\hline Parâmetros & Intervalo & $\mathrm{X} \pm \mathrm{EP}$ \\
\hline $\mathrm{N}^{\mathrm{o}}$ de ovos & $19-38$ & $(29,4 \pm 5,5)$ \\
Viabilidade de ovos (\%) & $65-98$ & $(84,9 \pm 11,6)$ \\
Período de Incubação (dias) & $17-25$ & $(20,6 \pm 1,0)$ \\
Tamanho do ovo (mm) & $3-5$ & $(4,5 \pm 3,7)$ \\
Larva ao eclodir (mm) & $4-6$ & $(5,0 \pm 3,7)$ \\
\hline
\end{tabular}

EP $=$ Erro padrão

As asas membranosas, nos machos são desenvolvidas e funcionais para o vôo (Fig. 1 C), enquanto que nas fêmeas, são reduzidas, com nervação vestigial e em formato de pequena lamina alongada e estreita (Fig. 1 D), não sendo funcional para vôo. Em algumas fêmeas foi observada uma fusão dos élitros, a partir do terço médio para a região posterior, caracterizando perda de função dessas estruturas para o inseto. Esse fenômeno nunca foi registrado anteriormente na literatura. Uma provável explicação para esse dimorfismo, tão acentuado, entre macho e fêmea seja devido a genes presentes nos cromossomos sexuais que não apresentam recombinação entre os dois sexos, e por isso, expressam apenas em um dos sexos durante a fase da diferenciação celular, proporcionando ou impedindo a formação de estruturas que caracterizam o referido dimorfismo na espécie.

Outras diferenças constatadas entre machos e fêmeas se referem à cor, ao tamanho das mandíbulas e o tipo de pernas. Os machos são na maioria de coloração preta, mas podem apresentar variações para a cor castanha escura ou castanha avermelhada (Fig. 2 A e B). Estes últimos foram coletados nos Municípios de Catanduva e Teodoro Sampaio. Já entre as fêmeas predominou-se a coloração castanha (Fig. 2 C).
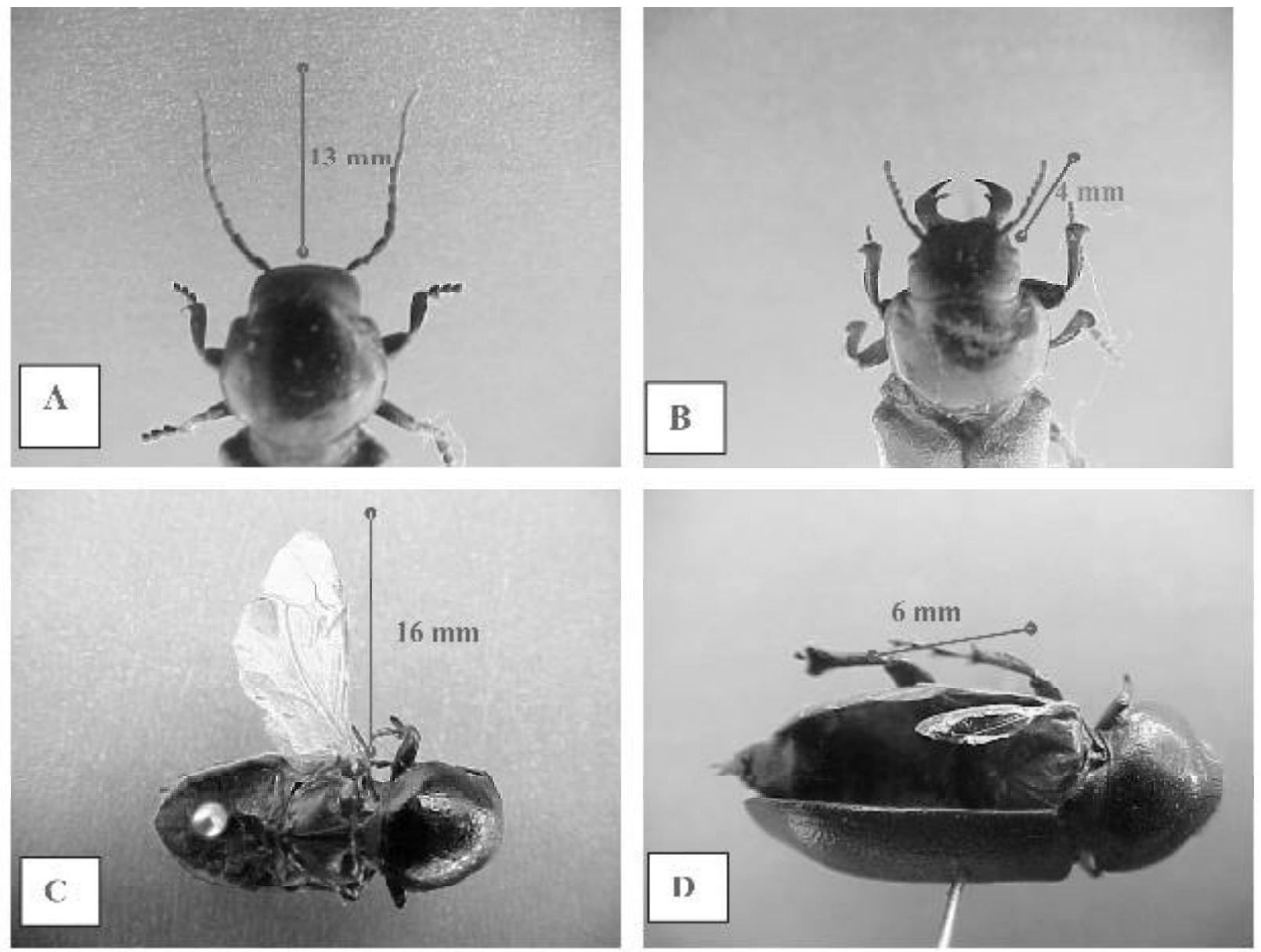

Fig. 1 - Aspectos morfológicos de adultos deMigdolus fryanus. A: antena do macho, B: antena da fêmea, C: asa do macho e D: asa atrofiada da fêmea. 
As mandíbulas são mais desenvolvidas nos machos quando comparadas com as fêmeas. Embora na fase adulta essa espécie não se alimenta, as mandíbulas são usadas para a saída do solo após a emergência; e o macho utiliza essa estrutura para imobilizar a fêmea durante a cópula (BENTO et al., 1995), assim como também durante a disputa com outros machos pela mesma fêmea. Com relação às pernas, nas fêmeas, são do tipo fossorial mais adaptadas para o escavamento que nos machos. Essas observações para M. fryanus, exceto a fusão de élitros das fêmeas, concordam com as relatadas por DiAs (1984) quando o autor examinou diversas coleções entomológicas para uma revisão do gênero.

Em alguns exemplares coletados em pastagens e cafénos Municípios de Bady Bassitt, SP, Potirendaba,
SP e Palestina, SP, foi observado uma redução nas mandíbulas (Fig. $3 \mathrm{~A}$ e B). Este fator pode estar relacionado com o fato desses insetos estarem presentes em solos com elevada camada de pedregulho, situada a uma profundidade variável de 40 a $60 \mathrm{~cm}$. Esta camada foi constatada mediante a abertura de trincheiras, com auxílio de retro-escavadeira.

Diante dessa camada, esses insetos ao atingir a fase adulta, encontram maior resistência para as mandíbulas, na ocasião da abertura da galeria para atingir a superfície do solo. Exemplares que apresentam essa característica terão menor chance de acasalamento, durante as revoadas, pois as mandíbulas auxiliam na contenção da fêmea durante a cópula e na sua concorrência com outros indivíduos da espécie.

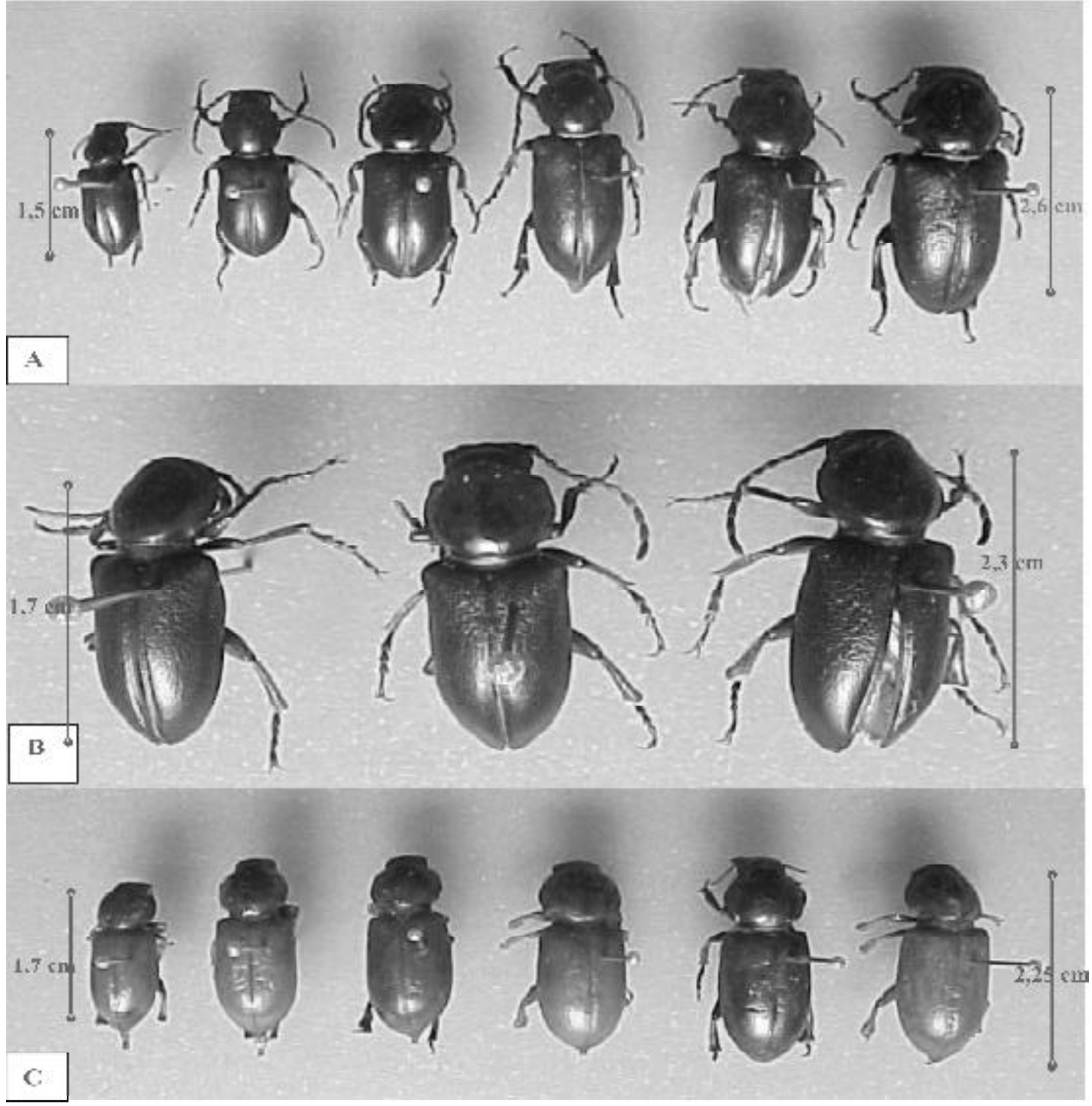

Fig. 2 - Coloração de machos e fêmeas deMigdolus fryanus. A: machos de coloração preta, B: machos de coloração marrom e C: fêmeas de coloração castanha. 


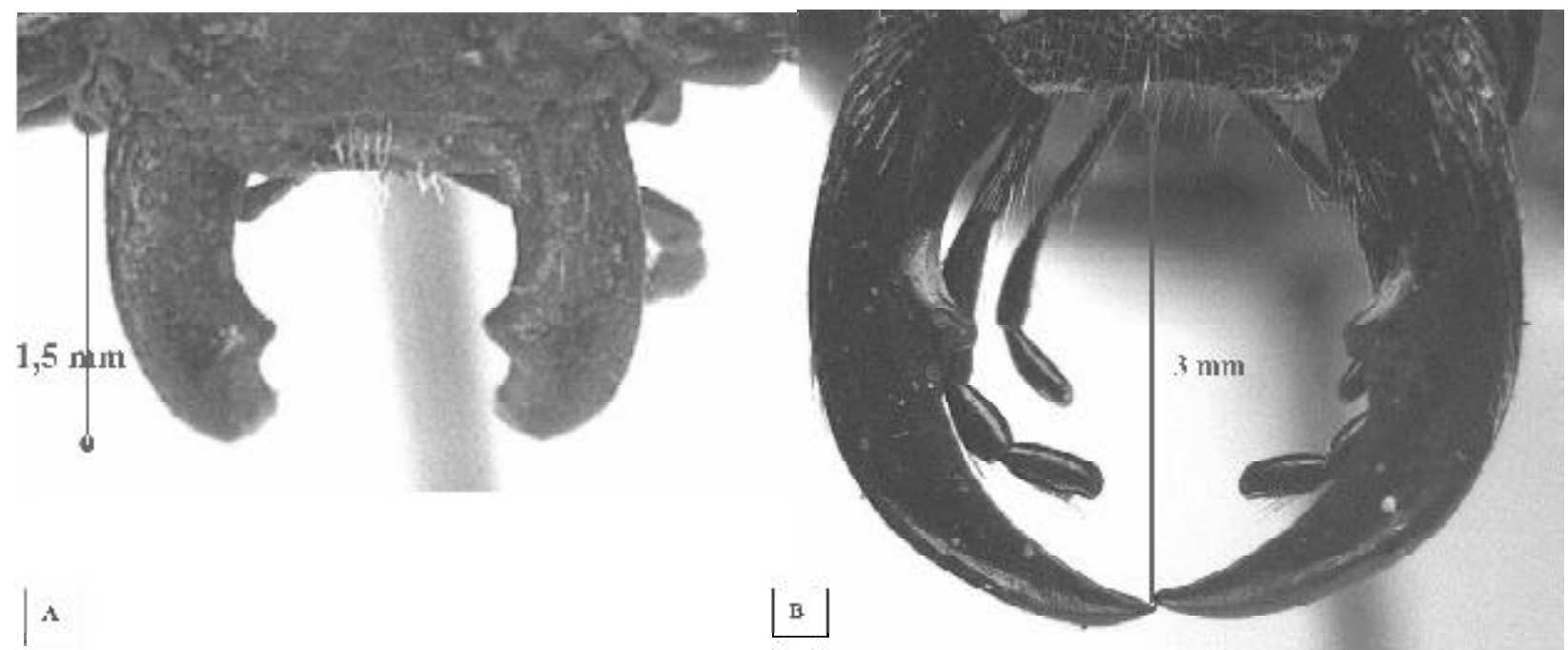

Fig. 3 - Migdolus fryanus. A: mandíbula com redução e B: mandíbula normal.

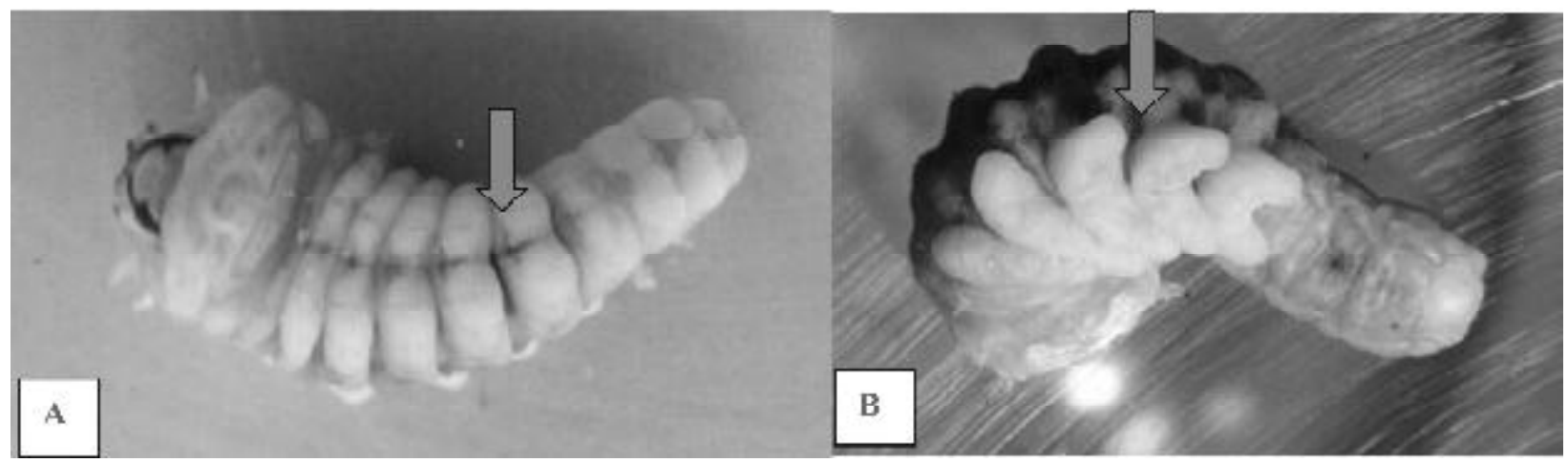

Fig. - 4 Larva deMigdolus fryanus.A: ampolas dorsais em formato de calombo, B: detalhe da projeção abdominal (ampolas ventrais).

\section{Larvas}

Larvas de $M$. fryanus são de formato cerambiciforme, com coloração branco-amarelada, (Fig. 4 A) sendo a cápsula cefálica levemente mais escura. As larvas observadas no final do desenvolvimento, mediam 4 a $5 \mathrm{~cm}$ de comprimento com 7 a $9 \mathrm{~mm}$ de largura no protórax. A porção anterior do corpo era mais alargada, com leve funilamento para a região posterior. A região ventral é plana sendo a dorsal convexa (Fig. 4 A). A segmentação do corpo é bem evidente sendo que nos segmentos anteriores (1 a 5) apresentam ampolas dorsais em formato de calombo. Na região ventral essas ampolas projetam para a lateral, sendo voltadas para parte posterior do corpo, em formato de arcos (Fig. 4 B). Essas estruturas têm a função de auxiliar no deslocamento da larva pelo interior da galeria no solo, como relatou FonsECA (1958).

As pernas nesta fase são atrofiadas, sendo o primeiro par mais desenvolvido que o segundo e o terceiro. A mandíbula é robusta, cortante e bem quitinizada, com os cantos arredondados. As antenas, nesta fase, também são rudimentares. Essas observações coincidem com as relatadas por CosTA et al. (1988), que examinaram material que se encontra depositado no Museu de Zoologia da USP em São Paulo, Brasil.

\section{Ovos e larvas de primeiro estádio}

Os ovos foram depositados no solo, sendo envolvidos por partículas do mesmo que ficam aderidas ao cório. Após serem depositados, apresentaram coloração branca leitosa (Fig. $5 \mathrm{~A}$ ), e ao longo do desenvolvimento embrionário, tornaram-se amarelados. No estágio final do desenvolvimento foi possível observar a região cefálica da larva. Isto, devido à coloração mais escura das mandíbulas. O cório do ovo, que possui formato elíptico é bastante frágil, sendo facilmente rompido por manipulações. $\mathrm{O}$ tamanho variou de 3 a $5 \mathrm{~mm}$, com média de $4,5 \pm 0,37$. Após a eclosão, as larvas mediram entre 4 a $6 \mathrm{~mm}$ de tamanho (Fig. 5 B). 


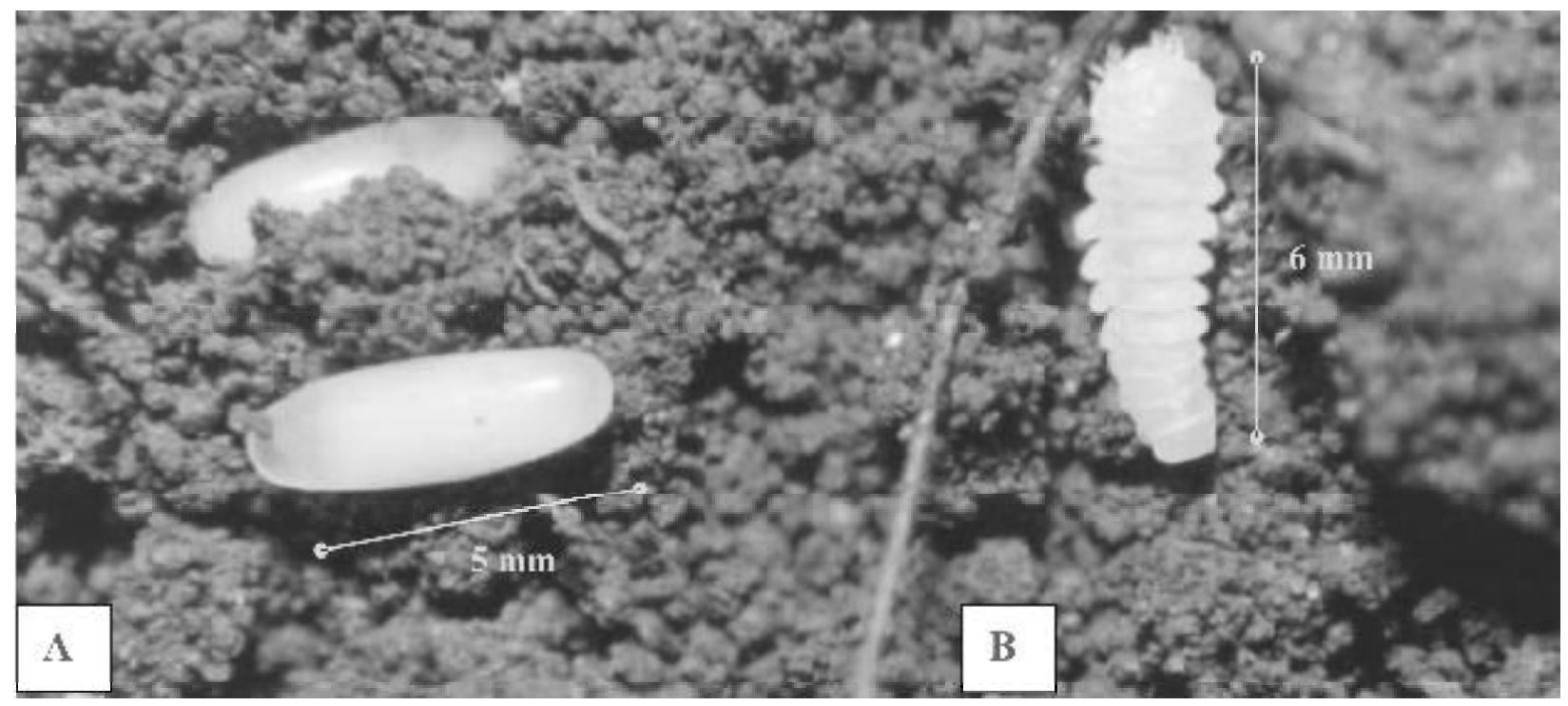

Fig. - 5 Migdolus fryanus. A: ovo, B: larva recém eclodida.

\section{CONCLUSÕES}

$\checkmark \quad$ Machos de $M$. fryanus apresentaram menor longevidade $(\bar{X} 5,8 \pm 1,9)$ que as femeas $(\bar{X} 32,5 \pm 3,5)$. Onúmero médio de ovos depositados por fêmea foi de $29,4 \pm 5,5$ que tiveram uma viabilidade média de 84,9 $\pm 11,6 \%$ e um período médio deincubação de $20,6 \pm 1,0$ dias.

$\checkmark$ A dieta artificial promoveu o desenvolvimento de larvas que tiveram 6 e 7 instares, mas não atingiram a fase de pupa.

$\checkmark$ Machos adultos são heterogêneos com relação ao comprimento do corpo, coloração e tamanho das mandíbulas.

$\checkmark \quad$ Nos municípios estudados apenas a espécie $M$. fryanus foi detectada nos canaviais e demais agroecossistemas.

\section{AGRADECIMENTOS}

Os autores agradecem a Fundação de Amparo a Pesquisa do Estado de São Paulo - FAPESP pelo financiamento das pesquisas.

A Usina Cerradinho Açúcar e Álcool, Destilaria Alcídia, EQUIPAV Açúcar e Álcool e Usina Guarani pelo apoio.

Ao Professor Manoel Martins Dias da UFSCAR pela colaboração nas observações morfológicas dos exemplares.

Ao Pesquisador Científico, Dr. Valmir Antonio Costa, do Instituto Biológico, pela elaboração das fotografias.
REFERÊNCIAS

Arrigoni, E.B.; Terán, F.O. Áreas afetadas por Migdolus spp (Coleoptera: Cerambycidae) em canaviais de unidades cooperadas. Boletim Técnico Copersucar, n.35, p.11-13, 1986.

Arrigoni, E.B. Aspectos biológicos de Migdolus fryanus (Westwood, 1863) (Coleoptera: Cerambycidae). In: CONGRESSO BRASILEIRODE ENTOMOLOGIA, 11., 1987, Campinas, SP. Resumos. Campinas, 1987. p.107.

Arrigoni, E.B. Flutuação populacional deMigdolusfryanus (Westwood, 1863) (Coleoptera: Cerambycidae). Boletim Técnico Copersucar, n.44, p.22-26, 1988.

Bento, J.M.S.; Albino F.E.; Della Lúcia T.M.C.; Vilela, E.F. Field trapping of Migdolus fryanus (Westwood, 1863) (Coleoptera: Cerambycidae) using natural sex pheromone. Journal of Chemical Ecology, v.18, n.2, p.245251, 1992.

Bento, J.M.S.; Vilela, E. F.; Della Lucia, T.M.C.; Leal, W.S.; Novaretti, W.R.T. Migdolus: biologia, comportamento, $e$ controle In: BENTO, J.M.S. (Ed.). Salvador, 1995. 58p.

BRUCH, C. Algunos interessantes Cerambicídos. Revistadel Museo de La Plata, n.25, p.345-356, 1921.

Costa, C.; V Anin, S.A.; CASARI-Chen, S.A.Larvas de coleoptera do Brasil.São Paulo: Museu de zoologia, Universidade de São Paulo, 1988. 282p.

Crowson, R.A. The natural classification of the families of Coleoptera. Oxford: E.W. Classey, 1955, 187p.

DiAs, M.M. Revisão da subfamília Anoplodermatinae. Parte I Tribo Anoplodermatini. Gênero Migdolus Westood, 1863. (Coleoptera: Cerambycidae). Revista Brasileira de Entomologia, v.28, n.4, p.507-535, 1984.

DuFF, E.A. A monograph of immature stages of British and imported timber beetles (Cerambycidae). London: British Museum (Natural History), 1953, VIII, 355p. 
Fonseca, J.P. Migdolus morretesi Lane (Coleoptera, Anoplodermidae), uma broca eventual da cana-deaçúcar e do eucalipto. Arquivos do Instituto Biologico, São Paulo, v.25, p.29-40, 1958.

Gounelle, E. Note sur le genre Migdolus et description de la femelle du Migdolusfryanus West. (Col.). Bulletinde la Societe Entomologique de France, p.276-277, 1899.

Guérin-Ménèville, F.E. Description de deux genres nouveaux de la famille des longicornes. Revista de Zoologia, p.276-277, 1840.

KastenJunior,P.;D OnZelLI,J.L.;StriniJunior,A.E.;SACOMANO, J.B.; VilHenA, E.O.Ocorrência de Migdolus spp. e insetos associados em solo de textura arenosa (Areias quartzosas). Boletim Técnico Copersucar, n.32, p.29-32, 1985.

LANE, F. Esboço monográfico dos anoplodermídeos. Revista do Museu Paulista, n.23, p.155-223, 1937.

Machado, L.A.; Berti Filho, E. Criação artificial da brocados-citros Diploschema rotundicolle (Serville, 1834) (Coleoptera: Cerambycidae). Biológico, São Paulo, v.61, n.1, p.5-11, 1999.

NaKano, O.; JoKo, T. Considerações sobre a biologia e hábito do Migdolus morretesi Lane, 1937 (Coleoptera, Cerambycidae). In: REUNIÃO ANUAL DA SOCIEDADE BRASILEIRA DE ENTOMOLOGIA, 2., 1973, Recife, PE. Resumos. Recife, 1973. p.6.

NaKano, O.; Romano, F.C.B.;P essini, M.M.O. (Eds.). Broca do rizoma (Migdolus spp.) In: Pragas de Solo. Piracicaba: ESALQ/USP, 2001. p.25-35.
Nunes, D.B. O estado da arte sobre Migdolus spp. (Coleoptera: Cerambycidae). In: WORKSHOP SOBRE MIGDOLUS, 1996, Tarumã. Resumos. Tarumã, 1996. p.5-10.

Roccia, A.O. Estudos sobre a bio-ecologia e controle de Migdolus spp. (Col.: Cerambycidae). Relatório Anual do Setor de Entomologia Copersucar, p.340-347, 1977.

Svácha, P.; WANG, J.; Chen, S. Larval morphology and biology of Philus antennatus and Heterophilus punctulatus, and systematic position of the Philinae (Coleoptera: Cerambycidae and Vesperidae)Annales de la Societe Entomologique de France (N.S.), v.33, n.3, p.323-369, 1997.

Teran, F.O.; Novaretti, W.R.T.; Kasten Junior, P. Migdolus sp. e insetos associados. In: REUNIÃO TÉCNICA AGRONÔMICA SOBRE PRAGASDA CULTURA DA CANA-DE-AÇÚCAR, 1983, Piracicaba. Anais. Piracicaba: Copersucar, 1983. p.25-31.

Teran, F.O.; Novaretti, W.R.T.; Kasten Junior, P.; Arrigoni, E.B.; Matos, C.A.O. Migdolus sp. e insetos associados. In: SEMINÁRIO DE TECNOLOGIA AGRONÔMICA, 2., 1984, Piracicaba. Resumos. Piracicaba: Centro de Tecnologia Copersucar, 1984. p.313-326.

Recebido em 17/5/06 Aceito em 27/10/06 